\title{
Autosomal dominant prognathism
}

INSERM

\section{Source}

INSERM. (1999). Orphanet: an online rare disease and orphan drug data base. Autosomal dominant prognathism. ORPHA:2964

Autosomal dominant prognathism is a rare, genetic, developmental defect during embryogenesis disorder characterized by abnormal forward projection of the mandible beyond the standard relation to the cranial base, with lower incisors often overlapping the upper incisors, that is inherited in an autosomal dominant manner. Association with mildly everted lower eyelids, flat malar area, thickened lower lip and craniosynostosis has been reported. 